\section{In Memoriam: Jimmie C. Holland, MD (1928-2017)}

\author{
Teresa L. Deshields, PhD, ABPP
}

Jimmie C. Holland, MD, died on December 24, 2017. As Lori Wiener, PhD, DCSW, LCSW-C, a pediatric social worker at NCI and a mentee of Dr. Holland, stated, "The world has lost a true and irreplaceable leader, the field of psycho-oncology has lost our pioneer, and we have lost a great friend."

Dr. Holland's accomplishments were many-far too many to be thoroughly recounted here. Most notably, she completed medical school in 1956, a time when few women were doing so. She selected psychiatry as her specialty area and was board certified in 1966. She married an accomplished oncologist, and this union set her on the path to develop the field of psycho-oncology. Her husband, James F. Holland, MD, was one of the co-founders of the Cancer and Leukemia Group B clinical trial cooperative group in 1976, where Dr. Jimmie Holland eventually formed a committee that began adding assessment of quality of life (and other psychosocial elements) into oncology clinical trials. She joined Memorial Sloan Kettering Cancer Center in 1977 and worked with colleagues there to create the first full-time psychiatry service in a cancer hospital. She continued to work at Memorial Sloan Kettering as a psychiatrist providing care to patients with cancer until her death.

Dr. Holland was the inaugural chair of the NCCN Distress Management Panel in 1997 and remained actively engaged in this role until her death. Paul Jacobsen, PhD, her long-time Panel Vice Chair and the Associate Director of NCI's Division of Cancer Control and Population Sciences, recalled an early meeting of the panel. "What I remember most clearly is Jimmie's skill in moving the group to consensus and engaging everyone in the work to be done. You left feeling that you had not just attended a meeting, but had joined a mission to bring the benefits of psychosocial care to all people affected by cancer. Jimmie's vision and leadership allowed us to 'think bigger' and accomplish much more than we believed possible when we started out."

With the NCCN Guidelines for Distress Management, Dr. Holland advocated for distress to be considered the "sixth vital sign," given its importance in the care and wellbeing of patients with cancer-a cause she championed for the remainder of her career. She was involved in the development of the Distress Thermometer, the most widely used distress screening tool in the world. The Distress Thermometer is an elegantly simple 0-10 rating scale for distress, with an associated broad-based problem list that allows patients to identify factors contributing to their distress. Her call for distress screening presaged the incorporation of distress screening as an accreditation standard for cancer centers by the American College of Surgeons Commission on Cancer in 2015.

By any standard, Dr. Holland had a distinguished academic career. She published more than 100 peer-reviewed journal articles. She edited the first textbook on psychooncology in 1989 and established the journal Psycho-Oncology in 1992. She received the American Cancer Society's Medal of Honor for Clinical Research in 1994. She served as a member of the Institute of Medicine's Committee on Psychosocial Services to Cancer Patients/Families in a Community Setting, which produced the seminal report "Cancer Care for the Whole Patient: Meeting Psychosocial Health Needs" in 2008. She was elected a fellow of the Institute of Medicine and the National Academy of Sciences.

Dr. Holland founded the American Psychosocial Oncology Society and the International Psycho-Oncology Society. She vigorously promoted a multidisciplinary approach to the psychosocial care of patients with cancer and actively engaged professionals from various disciplines in the activities and leadership of both organizations. She mentored many professionals in the growing field of psycho-oncology, fostering clinicians, researchers, and patient advocates.

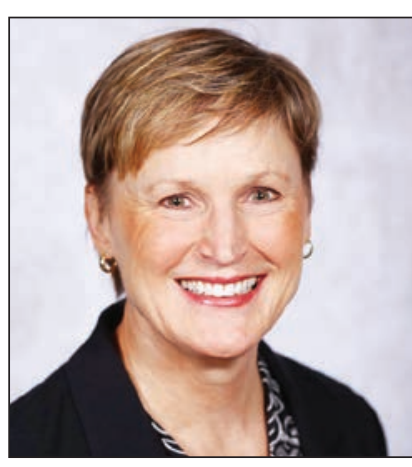

Teresa L. Deshields, PhD, ABPP

Teresa L. Deshields, PhD, ABPP, is a licensed clinical psychologist and manager of the Siteman Counseling Service for the Alvin J. Siteman Cancer Center at BarnesJewish Hospital and Washington University School of Medicine. She is also a Clinical Associate Professor in the Department of Medicine at the School of Medicine. She has worked at the Siteman Cancer Center since February 1999. Her clinical practice is devoted to treating patients with cancer, survivors, and their family members throughout the cancer continuum-diagnosis, treatment, survivorship, endof-life, and grief. Her research is focused on issues related to psychological adjustment and quality of life in patients with cancer and survivors.

doi: $10.6004 /$ jnccn.2018.0009

The ideas and viewpoints expressed in this commentary are those of the author and do not necessarily represent any policy, position, or program of NCCN. 
Deshields

Dr. Holland also had a rich and full life beyond her academic career. She had a long and fruitful marriage with Dr. James Holland. They modeled the dual-career couple, together raising 6 children, while establishing successful careers. She cherished her extended family, including 9 grandchildren.

Matthew Loscalzo, LCSW, Executive Director of the Department of Supportive Care Medicine at the City of Hope, wrote, "Jimmie is the mother of psycho-oncology and the soul of caring for people: patients, families, and our colleagues. She was a colleague, mentor, and seer." Many people have been touched by Dr. Holland's work, both professionally and personally. In the postings after her death, many shared how instrumental she was in promoting or molding their careers. Mr. Loscalzo added, "Ultimately Jimmie has left us, and for this we deeply mourn, and yet she remains alive every time we are bold in our compassionate expertise toward patients, families, colleagues, and ourselves."

Her death is a loss in so many ways, but her legacy will endure far into the future. 